\title{
The "Scrubbing Brush Technique" for Access to Tight Lateral Recess of the Sphenoid Sinus: A Single Case Report
}

\author{
Margaret Zhang *, Somasundram Subramaniam and Chew Lip Ng
}

check for updates

Citation: Zhang, M.; Subramaniam, S.; Ng, C.L. The "Scrubbing Brush Technique" for Access to Tight Lateral Recess of the Sphenoid Sinus: A Single Case Report. Sinusitis 2021, 5, 67-70. https://doi.org/10.3390/ sinusitis5010008

Academic Editor: Eleonora Nucera

Received: 15 February 2021

Accepted: 19 March 2021

Published: 1 April 2021

Publisher's Note: MDPI stays neutral with regard to jurisdictional claims in published maps and institutional affiliations.
Department of Otorhinolaryngology-Head and Neck Surgery, Ng Teng Fong General Surgery, National University Health System, Singapore 119228, Singapore; somasundram_subramaniam@nuhs.edu.sg (S.S.); Chew_Lip_Ng@nuhs.edu.sg (C.L.N.)

* Correspondence: Margaret_zhang@nuhs.edu.sg

\begin{abstract}
Access to the lateral recess has always been a difficult task, especially in cases where the entrance to the lateral recess is very narrow. Various strategies have been described to approach it. Our study proposes a unique method of clearing debris in patients with concretions within the lateral recess. The "scrubbing brush technique" is based on easily accessible tools and has the exceptional advantage of being user friendly and having minimal potential side effects.
\end{abstract}

Keywords: sinusitis; sphenoid sinus; mycetoma; lateral recess; technique

\section{Introduction}

The sphenoid sinus is one of four paired paranasal sinuses within the body of the sphenoid bone, with varying morphologies depending on the pattern of pneumatization [1,2]. The lateral recess of the sphenoid sinus poses a unique challenge to the sinus surgeon when the entrance to the lateral recess is narrow. The lateral recess is present when sphenoid pneumatization extends beyond a line connecting the medial edges of the extracranial opening of foramen rotundum and the vidian canal projecting towards the greater wing of sphenoid bone or body of pterygoid process or both [3-5] (Figure 1). Lesions in the lateral recess include mycetomas, CSF fistulae, meningoencephaloceles, and neoplasms. Many approaches have been described regarding endoscopic access to the sphenoid sinus, such as transeptal, transnasal, transethmoidal, and transpterygoid. Of these methods, the transpterygoid approach appears to be the most widely used to assess the lateral recess [6]. This approach has the potential for neurovascular damage, as the pterygopalatine fossa and its contents have to be traversed to assess the lateral recess [7]. We propose an innovative technique of clearing mycetomas and infected debris and concretions within the lateral recess, which we term the "scrubbing brush technique".

\section{Method}

A bendable stylet with a brush tip, used for unclogging microdebriders and suctions, can be bent at an angle, and used to access the lateral recess through a sphenoidotomy [8]. The stylet used was part of the equipment of the Xomed RAD 40 Curved Sinus Blade (Medtronic, Minneapolis, MN, USA). We demonstrated this in a patient undergoing endoscopic sinus surgery for sphenoid fungal sinusitis with a very narrow medial access to the lateral recess because of a high vidian nerve canal and low foramen rotundum (Video 1 and Figure 2). The access had a mere width of $3 \mathrm{~mm}$ upon CT scan. The narrow access would have made the removal of the fungal debris in the lateral recess challenging. 


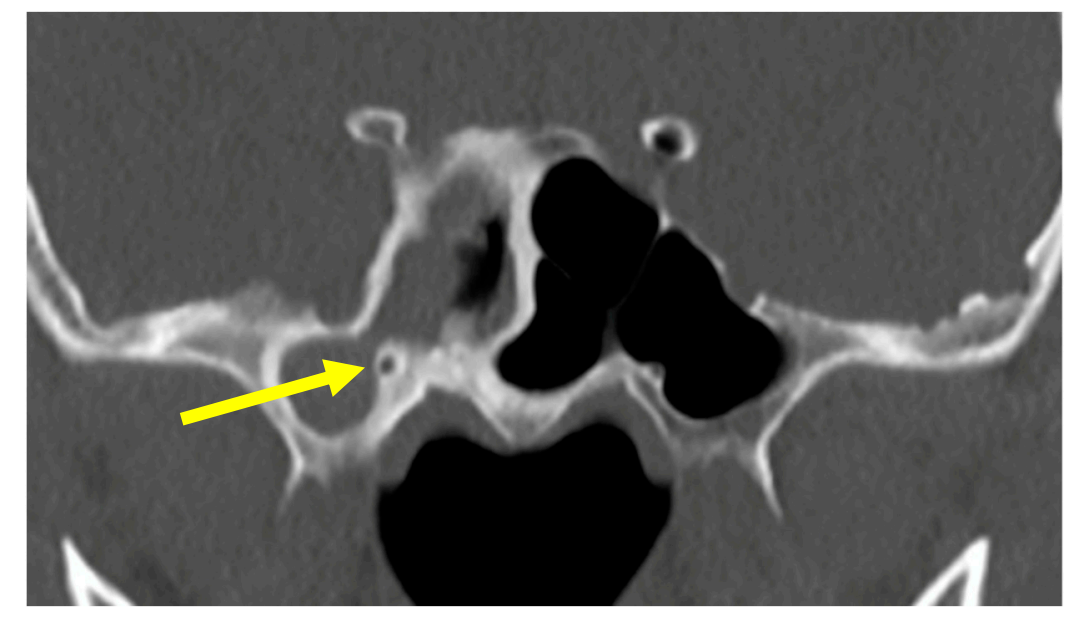

Figure 1. The sphenoid sinuses. The arrow indicates the narrow opening into the lateral recess.

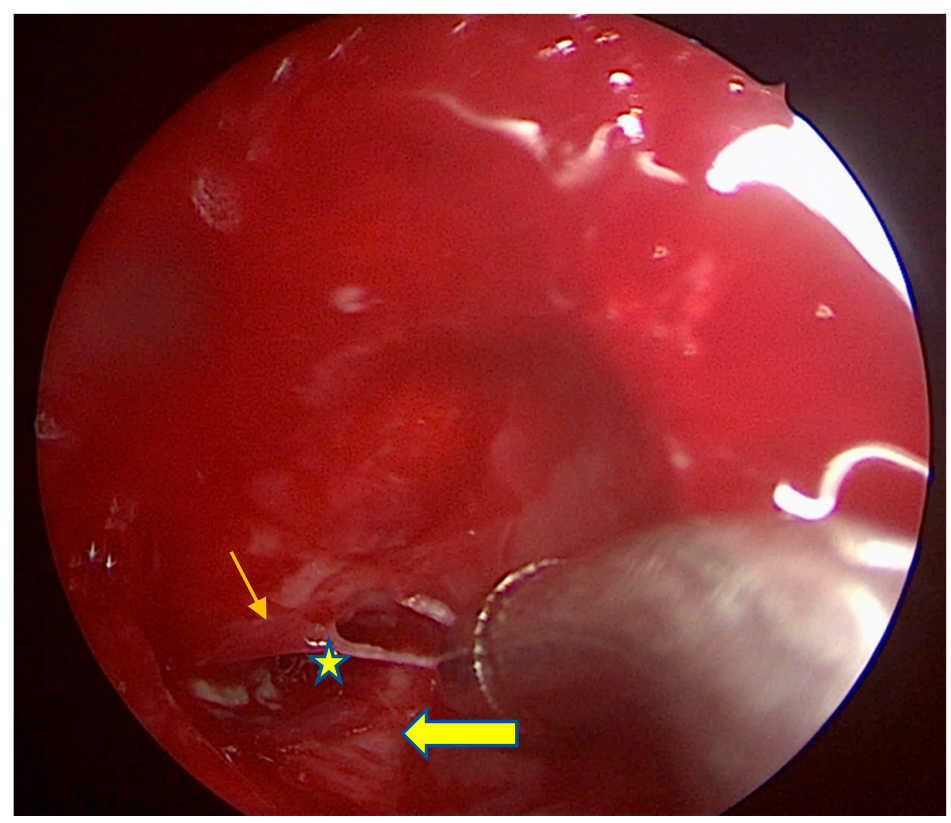

Figure 2. The view into the right sphenoid sinus. Thin arrow represents the foramen rotundum. Thick arrow represents the vidian canal. Star represents the tight opening into the lateral recess. The curved suction tip is too large to pass through the narrow opening into the lateral recess.

A wide sphenoidotomy was performed and the fungal material within the main sphenoid sinus removed. The stylet was bent at an angle, as shown in Figure 3. This was then inserted under direct visualization with a seventy degree rigid endoscope into the lateral recess of the right sphenoid sinus, and a scrubbing motion was then applied to move the brush in and out of the lateral recess, breaking up and drawing out the fungal debris from within. Any residual debris can be flushed out with saline easily, as they are broken up into smaller pieces by the scrubbing motion of the brush (Figure 4). 


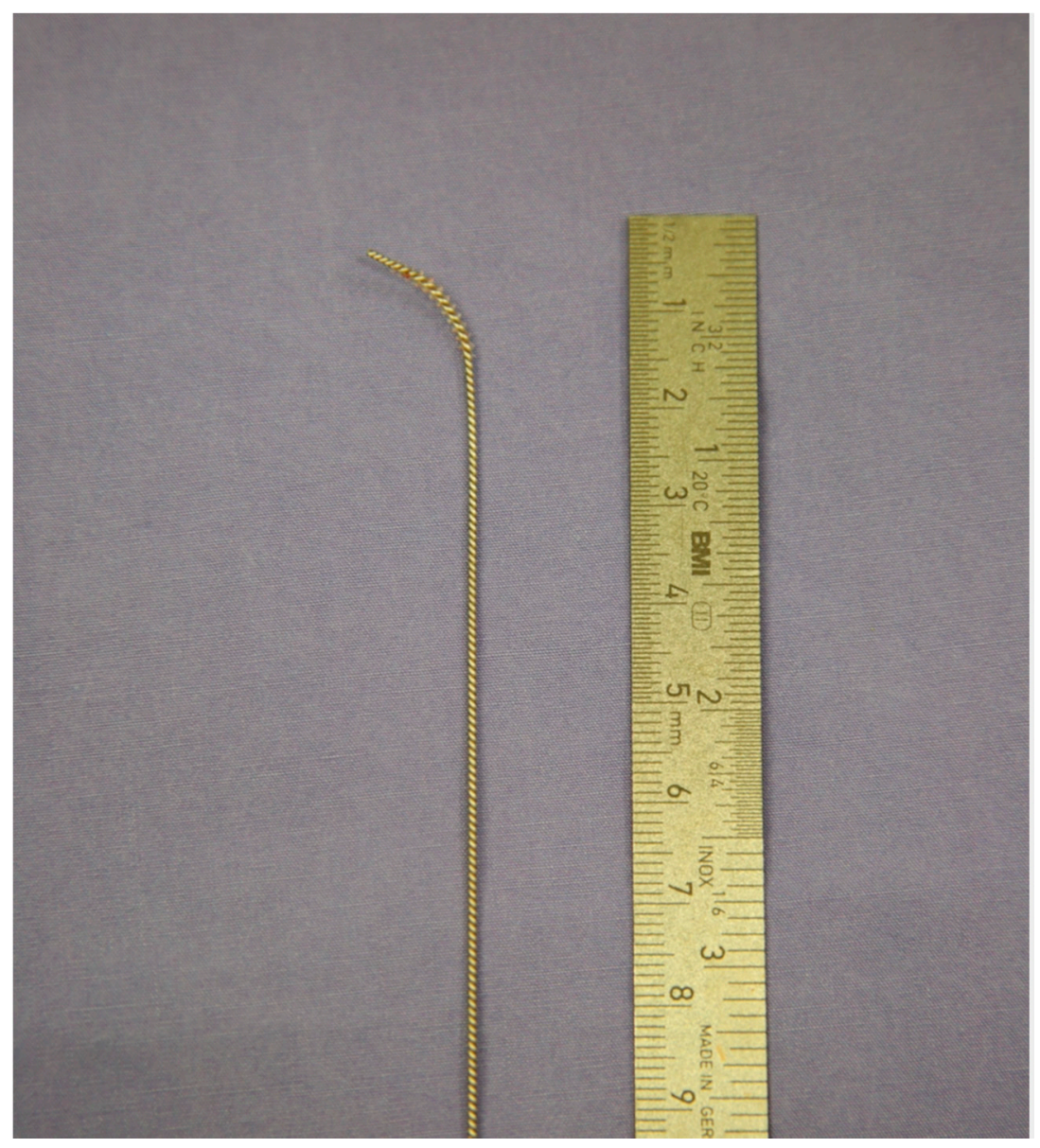

Figure 3. The stylet bent at an angle with a ruler next to it for comparison.

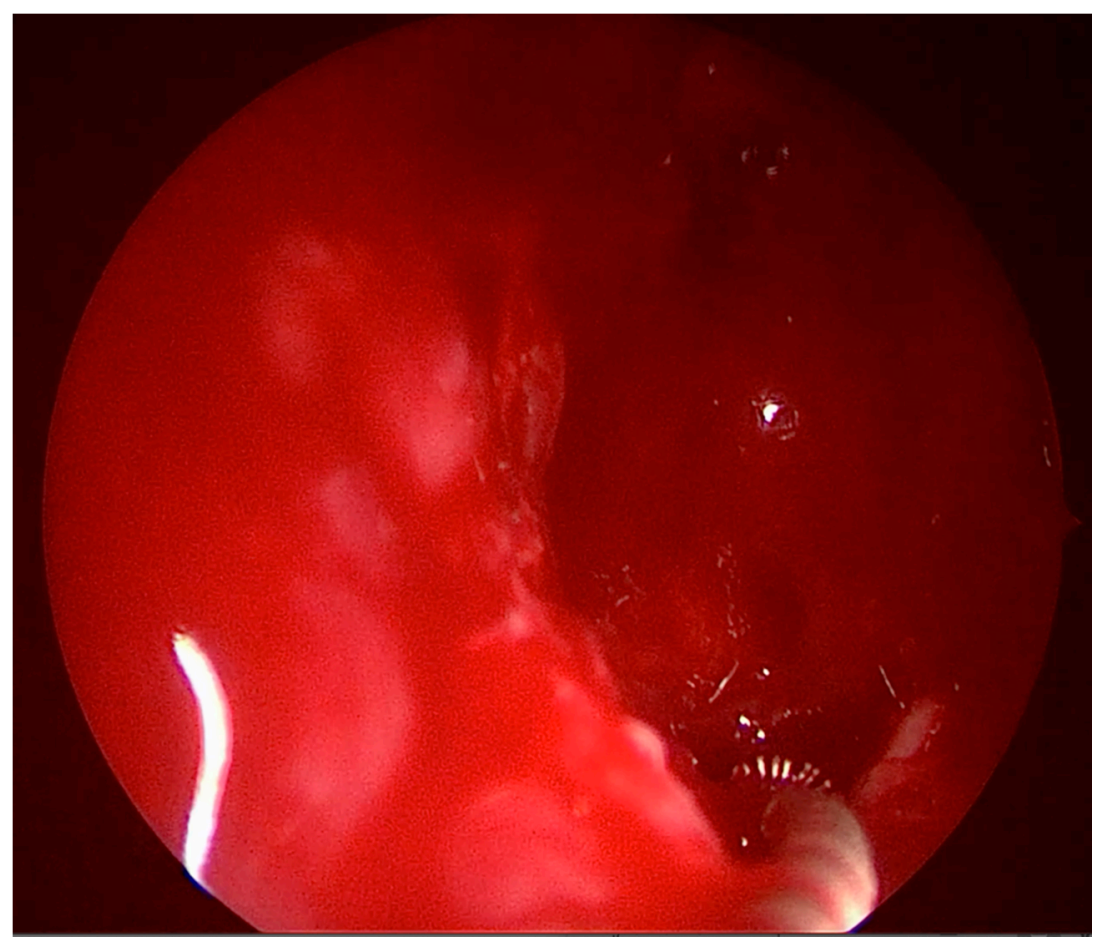

Figure 4. The stylet being inserted under direct supervision into the lateral recess. 


\section{Results}

The fungus was completely cleared, and the patient recovered uneventfully with no neurovascular damage. The operative time was greatly reduced, as there was no need for a transpterygoid approach.

\section{Discussion}

We propose that this technique can be used for patients with benign disease in the lateral recess, such as fungal sinusitis. We recommend that the placement of the brush in the lateral recess be under direct visualization, but the scrubbing motion can be performed without direct visualization into the lateral recess. This can be applied multiple times till the lateral recess disease is cleared adequately.

Potential pitfalls of this technique include the fact that the scrubbing motion itself could be blind, as blood might obscure the view as the brush is being applied. However, the stylet is in itself relatively pliable, and the risk of damage to the surrounding structures is low. This technique is not suitable for cases where there is possible communication with intracranial contents, such as a meningocoele or myelomeningocoele in a dehiscent Sternberg canal, due to the risk of cerebrospinal fluid leak, or for neoplasms. In cases where there is the possibility of dehiscence of the internal carotid artery, this technique should not be used due to the risk of puncturing the vessel.

\section{Conclusions}

In conclusion, we recommend a "scrubbing brush technique" as an approach to the lateral recess to clear infected sinus contents.

Author Contributions: Conceptualization, S.S. and C.L.N.; Methodology, M.Z., S.S. and C.L.N.; Project administration, M.Z.; Supervision, C.L.N.; Writing-original draft, M.Z.; Writing-review \& editing, S.S. and C.L.N. All authors have read and agreed to the published version of the manuscript.

Funding: This research received no external funding.

Informed Consent Statement: Informed consent was not required as there is no patient identifier.

Data Availability Statement: Data is contained within this article.

Conflicts of Interest: The authors declare no conflict of interest.

\section{References}

1. Jaworek-Troć, J.; Zarzecki, M.; Zamojska, I.; Iwanaga, J.; Przybycień, W.; Mazur, M.; Chrzan, R.; Walocha, J.A. The dimensions of the sphenoid sinuses-evaluation before the functional endoscopic sinus surgery. Folia Morphol. 2020. [CrossRef] [PubMed]

2. Jaworek-Troć, J.; Iwanaga, J.; Chrzan, R.; Zarzecki, J.J.; Żmuda, P.; Pękala, A.; Tomaszewska, I.M.; Tubbs, R.S.; Zawiliński, J.; Zarzecki, M.P. Anatomical variations of the main septum of the sphenoidal sinus and its importance during transsphenoidal approaches to the sella turcica. Transl. Res. Anat. 2020, 21, 100079. [CrossRef]

3. Govindaraju, R.; Tang, I.P.; Prepageran, N. Management of sphenoid lateral recess encephalocoeles. Curr. Opin. Otolaryngol. Head Neck Surg. 2019, 27, 37-46. [CrossRef] [PubMed]

4. Wang, J.; Bidari, S.; Inoue, K.; Yang, H.; Rhoton Jr, A. Extensions of the sphenoid sinus: A new classification. Neurosurgery 2010, 66, 797-816. [CrossRef] [PubMed]

5. Li, L.; London, N.R.; Prevedello, D.M.; Carrau, R.L. Endoscopic prelacrimal approach to lateral recess of sphenoid sinus: Feasibility study. Int. Forum Allergy Rhinol. 2020, 10, 103-109. [CrossRef] [PubMed]

6. Bolger, W.E. Endoscopic Transpterygoid Approach to the Lateral Sphenoid Recess: Surgical Approach and Clinical Experience. Otolaryngol. Neck Surg. 2005, 133, 20-26. [CrossRef] [PubMed]

7. Al-Nashar, I.S.; Carrau, R.L.; Herrera, A.; Snyderman, C.H. Endoscopic Transnasal Transpterygopalatine Fossa Approach to the Lateral Recess of the Sphenoid Sinus. Laryngoscope 2004, 114, 528-532. [CrossRef] [PubMed]

8. Lageju, N.; Pradhan, B.; Thapa, N. Endoscopic Sinus Surgery for Sinonasal Polyposis: Microdebrider or Conventional Instruments. JNMA J. Nepal. Med. Assoc. 2017, 56, 447-450. [CrossRef] [PubMed] 